\title{
In vitro Evaluation of Aqua Extracts of Some Botanicals against Maize Stem Borer, Busseola fusca F. (Lepidoptera: Noctuidae)
} Tadele Shiberu*

College of Agriculture and Veterinary Sciences, Department of Plant Sciences and Horticulture, Ambo University, Ethiopia

\begin{abstract}
The present study was conducted to determine the comparative efficacy and bioactivity of aqueous extracts of four botanicals (leaf, root bark, flower) under in vitro condition. Cypermethrin $1 \% \mathrm{G}$ was used as standard check and untreated control against maize stem borer in maize (Zea mays L.), during 2012 at Ambo Plant Protection Research Center, Ethiopia. The treatments were aqueous leaf extract of Nicotiana spp. L. and Cymbopogon citratus, root bark aqueous extract of Securidaca longepedunculata F., and flower extract of Chrysanthemum cinerariaefolium at $5 \%$ concentration. The cumulative data revealed that the standard check-Cypermethrin $1 \% \mathrm{G}$ at rate of $0.3 \mathrm{~kg} /$ hectare recorded significantly higher mean percent mortality of maize stem borer, Busseola fusca, over all the other treatments. Among the botanical extracts, C. cinerariaefolium and C. citrates $5 \%$ concentration was recorded higher efficacy mean mortality ( 75 and 58.33 ), respectively, against $B$. fusca within three days, and found to be at par with some of the other botanical extracts. The Nicotiana spp. leaf extracts and S. longepedunculata root bark extract showed significantly lower efficacy mean mortality.
\end{abstract}

Keywords: Botanical extracts; Stem borer; Busseola fusca; Maize; Cypermethrin

\section{Introduction}

Maize is an important crop in much of the developing world. It grows over a wide geographical range and variety of environments than any other cereal crops, and is the $3^{\text {rd }}$ most important cereal crop on global basis [1]. The national average yield of maize, which is about $17 \%$ of the cultivated area, and $27.77 \%$ of production yield distribution in meher season [2].

In Ethiopia, maize is the second most important cereal crop, followed by tef in area of production. It is produced on an average area of over 1.2 million hectare of land. It is also the second important crop in total production [2]. The national average yield of maize, which is about 2.2 tons per hectare, is well below the world average of about 3.7 tons per hectare, but slightly better than the previous year [2]. The poor performance of maize in Africa in general, and Ethiopia in particular, could be attributed to unfavorable agro-climatic conditions poor soil fertility, and the prevalence of numerous insect pests and diseases [1].

Busseola fusca $\mathrm{F}$. is considered to be the most important pest of maize in sub-Saharan Africa [3]. The average yield loss of maize caused by cereal stem borers in Ethiopia was estimated between 20-50\% [4]. The use of insecticides can be environmentally disruptive, and can also elimination of beneficial insects and accumulation of residues in the harvested produces [5]. Botanical insecticides have long been touted as attractive alternatives to synthetic chemical insecticides for pest management. Botanical pesticides are ecofriendly, economic, targetspecific and biodegradable. The botanical insecticides are greatest strength in their specificity, as most are essentially nontoxic and nonpathogenic to animals and humans. Considering the importance of ecofriendly approaches to manage the pests, the experiment was designed to determine relative efficacy of aqua extracts of some botanical against maize stem borer. The high costs of synthetic pesticides and associated toxicity risks discourage to integrate into insect pest management systems [6,7], the agro-ecological conditions and suitable for maize growing areas of Ethiopia, which are indispensable. Therefore, the present study was under taken to determine the aqua extracts of some botanicals against maize stem borer, Busseola fusca (F.) in vitro condition.

\section{Materials and Methods}

The in vitro experiment was conducted at Ambo Plant Protection Research Center of Ethiopia, during 2012. The six treatments were conducted in Complete Randomized Design (CRD), with three replications. The treatments were local tobacco (Nicotiana spp.) leaf aqua extract Violet tree (Securidaca longepedunculata) root bark water extract, Pyrethrum (Chrysanthemum cinerariaefolium), flower water extract, Lemon grass (Cymbopogon citrates) water extract Cypermethrin $1 \%$ G (Standard check) and untreated control. The botanical leaf aqua extracts were prepared by Venkat et al. [8]. Leaves of Local tobacco and Lemon grass were collected and cut into small pieces. The cut leaves were grounded and mixed with water at $5 \%$ concentration level i.e. 50 g leaves per 1 liters of water, then filtered through muslin cloth. The violet tree root bark was collected from underground part of the plant, washed, grinded in mortal, and then made a paste $50 \mathrm{~g}$ added and mixed with 1 liter of water (at 5\% concentration) level, and filtered through muslin cloth. Pyrethrum flower was prepared by $50 \mathrm{~g}$ of flower powder mixed with 1 liter of water (at $5 \%$ concentration) level was extracted and filtered with muslin cloth, and then $2 \mathrm{ml}$ extracts were sprayed on the ten larvae of $B$. fusca $3^{\text {rd }}$ and $4^{\text {th }}$ larval instars per petridish, and preserved food with pieces of maize stalk. The numbers of larvae were recorded before spray and every $24 \mathrm{~h}$ after botanicals application, till 3 days after sprayed, and the percent mortality rate of larvae over control was calculated.

The mortality data obtained in the different treatments were analyzed using the SAS computer software [9], was used to compared

${ }^{*}$ Corresponding author: Tadele Shiberu, College of Agriculture and Veterinary Sciences, Department of Plant Sciences and Horticulture, Ambo University, P.O. Box 107, Ambo, Ethiopia, E-mail: tshiberu@yahoo.com

Received April 16, 2013; Accepted May 20, 2013; Published May 25, 2013

Citation: Shiberu T (2013) In vitro Evaluation of Aqua Extracts of Some Botanicals against Maize Stem Borer, Busseola fusca F. (Lepidoptera: Noctuidae). J Plant Pathol Microb 4: 179 doi:10.4172/2157-7471.1000179

Copyright: (c) 2013 Shiberu T. This is an open-access article distributed under the terms of the Creative Commons Attribution License, which permits unrestricted use, distribution, and reproduction in any medium, provided the original author and source are credited. 
with the treatment effects, and the mean comparison were carried out by using Duncan's Multiple Range Test (DMRT).

\section{Results and Discussion}

The cumulative data pertaining to mean percent mortality of maize stem borer revealed that among all the treatments, the standard treatment was recorded to be significantly superior in efficacy against maize stem borer, as it recorded highest mean percent mortality of maize stem borer. However, among the botanical extracts, $C$. cinerariaefolium was the best treatment against maize stem borer, by recording $75 \%$ mortality rate after second and third day application of the botanicals. It was found to be on par (non-significant different from untreated control) with Nicotiana spp., S. longepedunculata, $C$. cinerariaefolium and C. citrates within 24 hours. The Nicotiana spp. and $S$. longepedunculata leaf extract at $5 \%$ concentration and root bark extract at $5 \%$ concentrations, respectively. These botanicals were found to be least in efficacy against maize stem borer, however, better over untreated control within three days. All the other treatments recorded significantly lower mortality rate, and were found to be at par with each other within 24 hours, but significantly $(\mathrm{P}<0.0001)$ superior over control after three days.

In the present study, it was found that the standard check, Cypermethrin $1 \% \mathrm{G}$ at rate of $0.3 \mathrm{~kg} /$ hectare proved to be the best treatment against maize stem borer, by recording highest mean percent reduction of $100 \%$. Similarly, the superior efficacy of pyrethrum flower against maize stem borer was well documented by several workers in the insect pest [10]. However, there is no report on the toxicity effect of C. citrates on Lepidopteran insects. Despite the wide spread local use of S. longepedunculata in different parts of Africa, no adequate scientific reports mention its toxicity. The few reports available were indicated its trypomocide and insect toxicity, where it was used as a storage grain preservative $[11,12]$.

Table 1 revealed that the effect of insecticidal plant extracts at $1^{\text {st }}, 2^{\text {nd }}$ and $3^{\text {rd }}$ day after treatment against maize stem borer. C. cinerariaefolium and $C$. citrates treatment gave highly significant $(\mathrm{p}<0.0001)$ better results in reducing the population of stem borer at 3 days, $S$. longepedunculata, $C$. cinerariaefolium, $C$. citrates and Nicotiana spp treatments indicated no significant $(\mathrm{p}>0.0001)$ differences, with control treatment in controlling the population of maize stem borer larvae within one day post treatment. However, Cypermethrin (standard check) treatment significantly $(\mathrm{p}<0.0001)$ controlled $100 \%$ mortality mean at 1 st day after spray application compared to other treatments. Equally, Nicotiana spp, S. longepedunculata, and C. citrates treatments did not show any significant differences with the control treatments in the control of maize stem borer at $1^{\text {st }}$ day after the post treatment.

\begin{tabular}{|l|l|l|l|}
\hline \multicolumn{4}{|l|}{ Days after application } \\
\hline Treatments & $1^{\text {st }}$ day & $2^{\text {nd }}$ day & $3^{\text {rd }}$ day \\
\hline Nicotiana spp. (local variety ) & $8.33^{\mathrm{b}}$ & $16.67^{\mathrm{c}}$ & $33.33^{\mathrm{c}}$ \\
\hline Securidaca longepedunculata & $0.00^{\mathrm{b}}$ & $8.33^{\mathrm{c}}$ & $33.33^{\mathrm{c}}$ \\
\hline Chrysanthemum cinerariaefolium & $0.00^{\mathrm{b}}$ & $75.00^{\mathrm{b}}$ & $75.00^{\mathrm{b}}$ \\
\hline Cymbopogon citratus & $0.00^{\mathrm{b}}$ & $16.67^{\mathrm{c}}$ & $58.33^{\mathrm{b}}$ \\
\hline Cypermethrin & $100.00^{\mathrm{a}}$ & $100.00^{\mathrm{a}}$ & $100.00^{\mathrm{a}}$ \\
\hline Control & $0.00^{\mathrm{b}}$ & $0.00^{\mathrm{c}}$ & $0.00^{\mathrm{d}}$ \\
\hline MSE & 7.45 & 16.24 & 10.21 \\
\hline CV (\%) & 28.33 & 24.98 & 20.41 \\
\hline
\end{tabular}

Note: Means with the same letter(s) are not significantly different.

Table 1: Efficacy of aqua extracts of some botanicals against maize stem borer, mortality percentage under in vitro condition during 2012
Afful et al. [13] reported that the effect of the methanol extract of S. longepedunculata on larvae of Callosobruchus maculatus on different concentrations rate showed valuable effect on reduction of larvae. This could be due to the presence of the methyl salicylate and other saponins found in the root of this plant, which might act as antifeedant. Stevenson et al. [14] confirmed the antifeedant properties of the compound found in the methanol extract of $S$. longepedunculata, and this might have caused the reduction in damage of grains treated with the methanol extract of $S$. longepedunculata, but in this study, it was lower mortality rate compared to other treatments.

This study concluded that $C$. cinerariaefolium and C. citrates aqua water extracts contributing in reducing maize stem borer over the untreated treatments and other botanicals. In the present study, two botanicals mentioned above could be very well utilized as alternative to synthetic insecticides for the management of maize stem borer, contains insecticidal substances that have potential for use as alternative crop protectants against maize stem borer. In the future, demonstrating the field efficacy of these bio-pesticides under different ecosystem in various economically important insect pests, including maize stem borer is crucial.

\section{Acknowledgement}

I would like to acknowledge Professor T. Salvaraj for contributed his time to valuable critical comments on this paper.

\section{References}

1. CIMMYT, EARO (1999) Maize production Technology for the future; Challenges and opportunities. Proceeding of the sixth Eastern and Southern Africa Regional Maize conference, 21 - 25 September, 1998. Addis Ababa, Ethiopia

2. CSA (2012) Agricultural Sample Survey 2004 E.C report on area and production for major crops (private peasant holding Meher season). Statistical Bulletin Volume 1, CSA, Addis Ababa, Ethiopia.

3. Emana G, Tsedeke A (1999) Management of stem borer using sowing date at Arsi-Negele pest management journal of Ethiopia, Vol. 3 47-51.

4. Emana G (2001) Ecological management of cereal stem borer in Ethiopia. Proceeding of the 7th Eastern and Southern Africa Regional conference Nairobi, Kenya.

5. Anand P, Jagadiswari R, Nandagopal V (2008) Future of botanical pesticides in rice, wheat, pulses and vegetables pest management. Journal of Biopesticides 1: 154-169.

6. Mihale MJ, Kishimba MA (2004) Contamination of water and sediments by obsolete pesticides at Vikuge Farm, Kibaha District, Tanzania. Tanz J Sci 30 21-32

7. Ogendo JO, Deng AL, Belmain SR, Walker DJ, Musandu AO, et al. (2004) Pest status of Sitophilus zeamais Motschulsky (Grain Pests Management Practices). In: Subsistence Agric: A Case of farmers in Suba District, Nyanza Province, Coleoptera: Curculionidae, control. methods and constraints to safe maize grain storage Kenya. Egerton J Sci Technol Series 5: 175-193.

8. Venkat R, Sunitha D, Vishnu VR (2012) Evaluation of botanical and othe extracts against plant hoppers in rice. Journal of Biopesticides 5: 57-61.

9. SAS (2000) The SAS system for windows, version 8.0. SAS, Institute, Cary, NC, USA.

10. Casida JE, Quistad GB (1995) Pyrethrum flowers' production, Chemistry, Toxicology, and Uses. Oxford University Press, Oxford, UK

11. Atawodi SE, Bulus T, Ibrahim S, Ameh DA, Nok AJ, et al. (2003) In vitro trypanocidal effect of methanolic extract of some Nigerian Savannah Plants. Afr J Biotechnol 2: 317-321.

12. Belmain SR, Neal GE, Ray DE, Golob P (2001) Insecticidal and vertebrate toxicity associated with ethnobotanicals used as post harvest protectants in Ghana. Food Chem Toxicol 39: 287-291. 
Citation: Shiberu T (2013) In vitro Evaluation of Aqua Extracts of Some Botanicals against Maize Stem Borer, Busseola fusca F. (Lepidoptera: Noctuidae). J Plant Pathol Microb 4: 179 doi:10.4172/2157-7471.1000179

Page 3 of 3

13. Afful E, Owusu O, Obeng-Ofori D (2012) Bioactivity of S. longepedunculata Fres. against Callosobruchus maculatus Fab. (Coleoptera: Bruchidae) and Sitophilus zeamais Motsch (Coleoptera: Curculionidae).
14. Stevenson PC, Dayarathna TK, Belmain SR, Veitch NC (2009) Bisdesmosidic aponins from Securidaca longepedunculata roots: Evaluation of deterrency and toxicity to Coleopteran storage pests. J Agric Food Chem 57: 8860-8867. 